\title{
Alendronate improves QOL of postmenopausal women with osteoporosis
}

\author{
This article was published in the following Dove Press journal: \\ Clinical Interventions in Aging \\ 15 April 2010 \\ Number of times this article has been viewed
}

\author{
Hisaya Kawate' \\ Keizo Ohnaka ${ }^{2}$ \\ Masahiro Adachi' \\ Suminori Kono ${ }^{3}$ \\ Hideyuki Ikematsu ${ }^{4}$ \\ Hisashi Matsuo ${ }^{5}$ \\ Kazumi Higuchi ${ }^{6}$ \\ Takehiko Takayama ${ }^{7}$ \\ Ryoichi Takayanagi' \\ 'Department of Medicine and \\ Bioregulatory Science, Graduate \\ School of Medical Sciences, \\ Kyushu University, Fukuoka, Japan; \\ ${ }^{2}$ Department of Geriatric Medicine, \\ Graduate School of Medical Sciences, \\ Kyushu University, Fukuoka, Japan; \\ ${ }^{3}$ Department of Preventive Medicine, \\ Faculty of Medical Sciences, Kyushu \\ University, Fukuoka, Japan; ${ }^{4}$ Internal \\ Medicine, Haradoi Hospital, Fukuoka, \\ Japan; ${ }^{5}$ Matsuo Naika Hospital, \\ Fukuoka, Japan; ${ }^{6}$ Fukuoka Teishin \\ Hospital, Fukuoka, Japan; ${ }^{7}$ Takayama \\ Icho-ka and Naika Clinic, Fukuoka, \\ Japan
}

Purpose: Postmenopausal osteoporosis causes bone fracture as well as pain, physical, psychological and socially adverse effects, which affects a patient's quality of life (QOL). The effect of alendronate on QOL was investigated compared with that of alfacalcidol in postmenopausal osteoporotic women.

Patients and methods: A total of 44 postmenopausal osteoporotic women (mean age 69.8 years) with back or joint pain, although capable of walking, were randomly assigned to two groups; group A $(n=25)$ received $5 \mathrm{mg}$ /day of alendronate, and group $B(n=19)$ received $0.5 \mu \mathrm{g}$ /day of alfacalcidol, for the first 4 months. For the following 2 months, the group A received $0.5 \mu \mathrm{g} /$ day of alfacalcidol and the group $\mathrm{B}$ received $5 \mathrm{mg} /$ day of alendronate in a crossover design. The patient's QOL was evaluated by score of Japanese Osteoporosis Quality of Life Questionnaire (JOQOL), and pain intensity using a visual analog scale (VAS). Bone metabolism was measured by bone mineral density (BMD) and a biomarker for bone resorption, urinary crosslinked N-terminal telopeptide of type I collagen (NTX).

Results: With 4-month treatment, alendronate, but not alfacalcidol, improved pain-related QOL, reduced joint pain by VAS, and increased bone mineral density. Both treatments significantly reduced bone resorption, the inhibition was significantly higher with alendronate $(-56.5 \%)$ compared with alfacalcidol (-18.1\%). After crossover, the patients in group A received alfacalcidol and had a reduced total and daily living activity-related QOL scores, and increased upper back pain by VAS. The group B received alendronate had significantly reduced bone resorption after the 2 months.

Conclusion: Alendronate improves the QOL of Japanese postmenopausal women with osteoporosis by reducing pain intensity as well as increasing bone mineral density.

Keywords: osteoporosis, bisphosphonates, quality of life, pain, vitamin D

\section{Introduction}

Patients affected by age-related diseases have been increasing in recent years as the numbers of our elderly population has been increasing. This is especially so for the condition of postmenopausal osteoporosis which frequently causes impaired the physical, psychological and social life of the patients due to bone fractures or pain; in addition it also an added health care burden to society. ${ }^{1-6}$ Thus, it is important to find osteoporosis treatment which can maintain or improve a patient's quality of life (QOL) as well as prevent bone fracture. Bisphosphonates have been developed as osteoporosis drugs which improve pain in lower back as well as QOL in the patients suffering this condition to increase bone mass by inhibiting bone resorption and by preventing bone fracture. ${ }^{7-9}$ This is especially so for alendronate which reduces pain and improves QOL more effectively, than compared to calcium monotherapy, in post menopausal women

submit your manuscript $\mid$ www.dovepress.con 
in osteoporosis. However, the effect of bisphosphonates on improving QOL in osteoporotic patients has not been reported in a randomized controlled study in Japan to date. In the present study, we examined the effect of alendronate on QOL and pain in postmenopausal Japanese women with osteoporosis using a randomized comparative crossover design. Alfacalcidol was used as a comparative drug, as it has been reported to reduce the low back pain in an earlier double-blind study in Japan. ${ }^{10}$

\section{Materials and methods}

\section{Study design}

This is a randomized comparative study conducted in post menopausal women with osteoporosis who had been recruited in the outpatient clinics of 10 medical institutions within the Fukuoka prefecture, Japan, who were suffering pain in the lower back, the upper back or joints, although they were capable of walking. Osteoporosis was defined by criteria given by the Japanese Society for Bone and Mineral Research as; less than $70 \%$ of bone mineral density of the young adult mean $(\mathrm{T}$-score $<-2.5)$. The patients were excluded if they had osteomalacia, renal dysfunction (serum creatinine $>1.5 \mathrm{mg} / \mathrm{dL}$ ), malignant tumor, insulin therapy and bisphosphonates therapy within 6 months. The study prohibited the use of drugs which might affect bone metabolism such as calcitonin, ipriflavone, vitamin $\mathrm{K}$, and estrogen products. Patients who had been taking anti-inflammatory drugs, including patches and cream did not change either the drug and/or the dosage postregistration. The patients who initially required long-term treatment with anti-inflammatory drugs were excluded. At the baseline, patients were interviewed for family history of osteoporosis, pain and QOL assessment. X-rays of the lumbar vertebrae were taken to examine the presence of bone fracture.

A total of 44 registered patients were centrally randomized into two groups; group A $(\mathrm{n}=25)$ receiving $5 \mathrm{mg} / \mathrm{day}$ of alendronate for the first 4 months and $0.5 \mu \mathrm{g} /$ day of alfacalcidol for the following 2 months, and group B $(n=19)$ receiving $0.5 \mu \mathrm{g} /$ day of alfacalcidol for the first 4 months and $5 \mathrm{mg} /$ day of alendronate for the following 2 months as shown in Figure 1. The data of 10 patients were excluded from the analysis as; 4 patients did not have QOL data and 3 patients

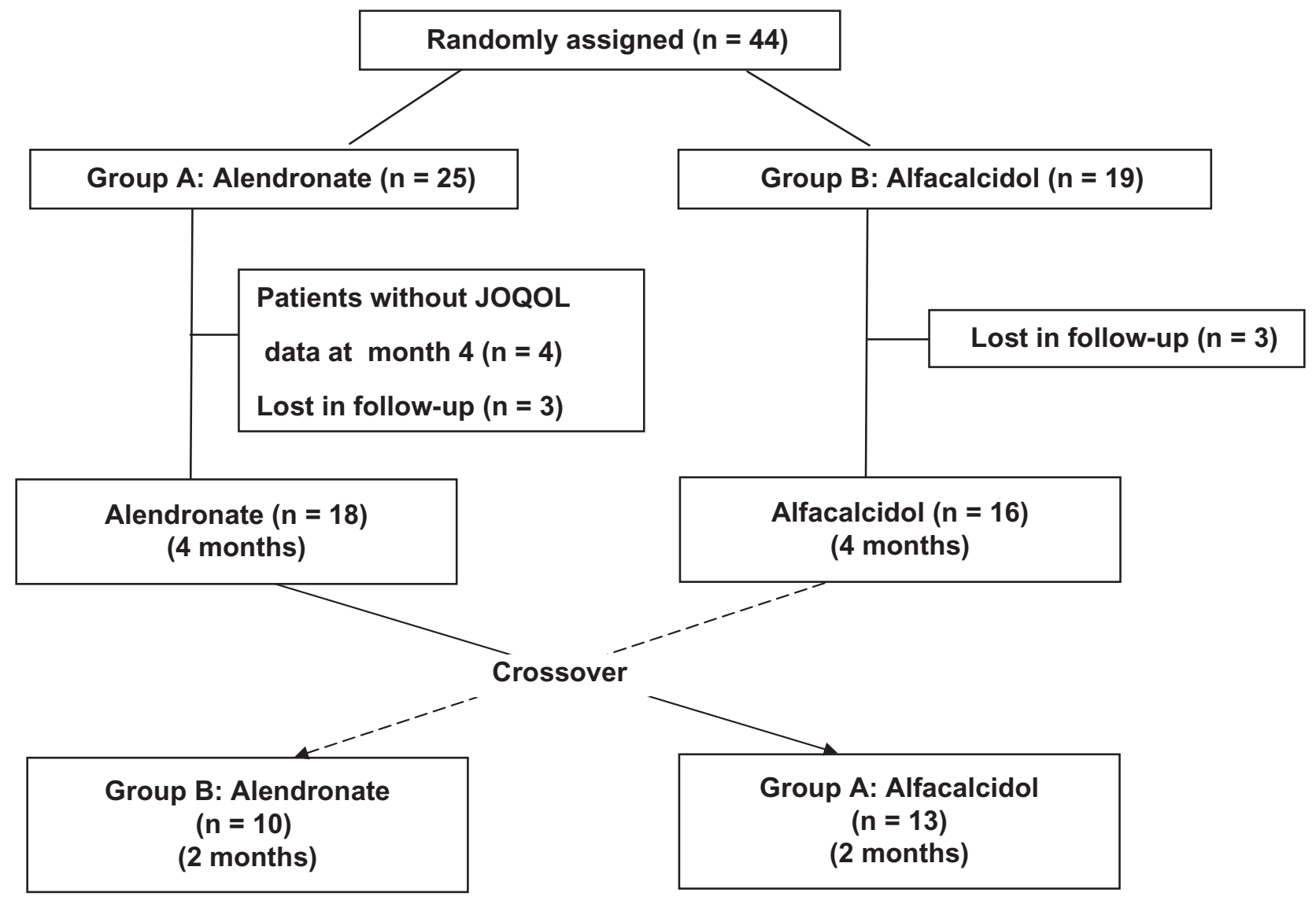

Figure I Enrollment and outcomes. Abbreviation:JOQOL, Japanese Osteoporosis Quality of Life Questionnaire. 
were lost in the follow-up of group A, and 3 patients were lost in the follow-up of group B. The data of 34 patients, 18 patients in the group A and 16 patients in the group B, were analyzed in the present study for the first 4 months. A total of 13 patients in the group A and 10 patients in the group B who completed the additional 2 months study after the crossover, were included for analysis.

The differences in QOL and pain were evaluated between alendronate treatment and alfacalcidol treatment with the following methods.

For the primary endpoint, a change in patient QOL, the QOL was assessed by Japanese Osteoporosis Quality of Life Questionnaire (JOQOL) consisting with 38 questions in six categories (pain, daily living activity, recreational and social activities, general health conditions, posture and figure, falls and the psychological effects pertaining to the condition) at the baseline, at 4 and 6 months. Patient response to each question was scored using a points scale from 0 to 4 ; giving 4 points at maximum. ${ }^{11}$ The six categories included areas related to: "pain" (5 questions with total of 20 points); "daily living activity" (16 questions with 64 points); "recreational and social activities" (5 questions with 20 points); "general health condition" (3 questions with 12 points); "posture and figure" (4 questions with 16 points); and "fall and its psychological effects" (5 questions with 20 points); with total of 152 points. The higher score indicated a higher QOL.

Pain was also assessed by visual analog scale (VAS) of 10 points at the baseline, 4 and 6 months for pain in the upper back, the lower back and the joints. Bone mineral density of lumbar vertebrae was measured by dual X-ray absorptiometry (DXA) at the baseline and 4 months. It was measured at Kyushu University and Fukuoka Teishin Hospital with the same measuring devices, QDR_4500 (Hologic, Tokyo, Japan). Bone resorption was measured by the marker, urinary crosslinked N-terminal telopeptide of type I collagen (NTX) at the baseline then at 4 and 6 months. All biochemical markers were measured centrally at SRL (Special Reference Laboratories, Tokyo, Japan). The observation period after the crossover was limited to 2 months for ethical reasons, since exacerbation of the clinical condition was previously observed in the patients who had switched from alendronate to alfacalcidol.

\section{Statistical analysis}

We focused on improvements on the pain score in estimating the required sample size in each group. Because of a lack of information about expected improvement in the pain score and its variation, we calculated the sample sizes under different conditions with a two-sided significance level of
0.05 and $80 \%$ power. We also assumed that the standard deviation (SD) for improvements was 5 points. When the improvements in the pain score were 3,4 or 5 points by the alendronate treatment, the required sample sizes were estimated to be 22, 13 and 8, respectively.

The values were expressed as mean \pm SD. The differences in baseline characteristics among groups were evaluated by a Chi-square test, Student's T-test, or ANOVA, followed by Tukey test. The differences in scores between the two groups were evaluated by Mann-Whitney $U$ test. The differences in percent change of bone marrow density (BMD) or NTX within the same group was evaluated between the baseline and that of 4 months or 6 months with ANOVA followed by Tukey test. The difference with $P<0.05$ was considered to be significant.

All statistical calculations were performed with SPSS (SPSS Inc., Chicago, IL, USA), and/or Statistica (StatSoft, Tulsa, OK, USA) computer software.

\section{Results}

The baseline characteristics of 34 patients who completed the first 4 months of treatment were compared between the two groups as shown in Table 1. No significant differences in age, BMD, or the incidence of lumbar vertebral fracture were observed between the two groups. Pain intensity using the VAS in joints $(4.2 \pm 2.0$ versus $2.7 \pm 1.8)$ and QOL impairment in "recreational and social activities" were significantly higher in the group A (alendronate) and the number of patients with a family history of osteoporosis were significantly higher in the group B (alfacalcidol).

During the first 4-month treatment, the patient QOL according to the total QOL score indicated a tendency to improve with both alendronate and alfacalcidol. Although alfacalcidol significantly improved the total QOL score, the average changes were similar between the two treatments (Figure 2). Furthermore, the pain related QOL was significantly improved by alendronate, but not by alfacalcidol, according to the QOL scores of six categories.

Based on VAS, the pain intensity of joints was significantly reduced by alendronate, while the intensity did not significantly change in any regions by alfacalcidol (Figure 3 ).

Although a tendency of increased BMD of the lumbar vertebrae was observed in both groups, only the treatment with alendronate significantly increased the BMD from the baseline with the 4-month alendronate treatment $(0.637 \pm$ 0.149 versus $0.659 \pm 0.159, P<0.001$ ) (Figure $4 a$ ). Furthermore, both alendronate and alfacalcidol reduced bone resorption as measured by urinary NTX. Alendronate significantly 
Table I Baseline patient characteristics

\begin{tabular}{|c|c|c|c|c|}
\hline Characteristic & & Group A $(n=18)$ alendronate & Group B $(n=16)$ alfacalcidol & $P$ value \\
\hline Age (year) & & $66.7 \pm 9.1$ & $72.7 \pm 8.1$ & ns \\
\hline BMD Lumbar vertebrae $\left(\mathrm{g} / \mathrm{cm}^{2}\right)$ & & $0.637 \pm 0.149$ & $0.628 \pm 0.137$ & ns \\
\hline Urinary NTX (nM BCE/nM Cr) & & $56.4 \pm 25.4$ & $53.0 \pm 23.4$ & ns \\
\hline Vertebral fractures at baseline (yes/no) & & $4 / 13$ & $4 / 12$ & ns \\
\hline Family history of osteoporosis (yes/no) & & $3 / 15$ & $9 / 7$ & $<0.05$ \\
\hline VAS (lower back) & & $4.8 \pm 2.4$ & $3.3 \pm 1.7$ & ns \\
\hline VAS (upper back) & & $3.1 \pm 2.1$ & $3.1 \pm 2.3$ & ns \\
\hline VAS (joints) & & $4.2 \pm 2.0$ & $2.7 \pm 1.8$ & $<0.05$ \\
\hline \multicolumn{5}{|l|}{ JOQOL } \\
\hline Pain & (20 points) & $12.3 \pm 4.3$ & $13.5 \pm 4.0$ & ns \\
\hline Activity of daily living & (64 points) & $58.1 \pm 8.0$ & $56.8 \pm 10.4$ & ns \\
\hline Recreational and social activities & (20 points) & $11.6 \pm 4.9$ & $8.3 \pm 4.8$ & $<0.05$ \\
\hline General health & ( 12 points) & $7.5 \pm 3.3$ & $7.1 \pm 3.2$ & ns \\
\hline Posture and figure & ( 16 points) & $10.0 \pm 4.4$ & $9.6 \pm 2.3$ & ns \\
\hline Falls and the psychological effects & (20 points) & $12.8 \pm 3.8$ & $11.8 \pm 3.6$ & ns \\
\hline Total QOL score & (152 points) & $73.3 \pm 12.3$ & $\begin{array}{l}70.4 \pm 10.0 \\
n s\end{array}$ & ns \\
\hline
\end{tabular}

Abbreviations: NS, not significant; QOL, quality of life; VAS, visual analog scale; JOQOL, Japanese Osteoporosis Quality of Life Questionnaire; BMD, bone mineral density; NTX, urinary crosslinked N-terminal telopeptide of type I collagen, BCE, bone collagen-equivalent; $\mathrm{Cr}$, creatinine.

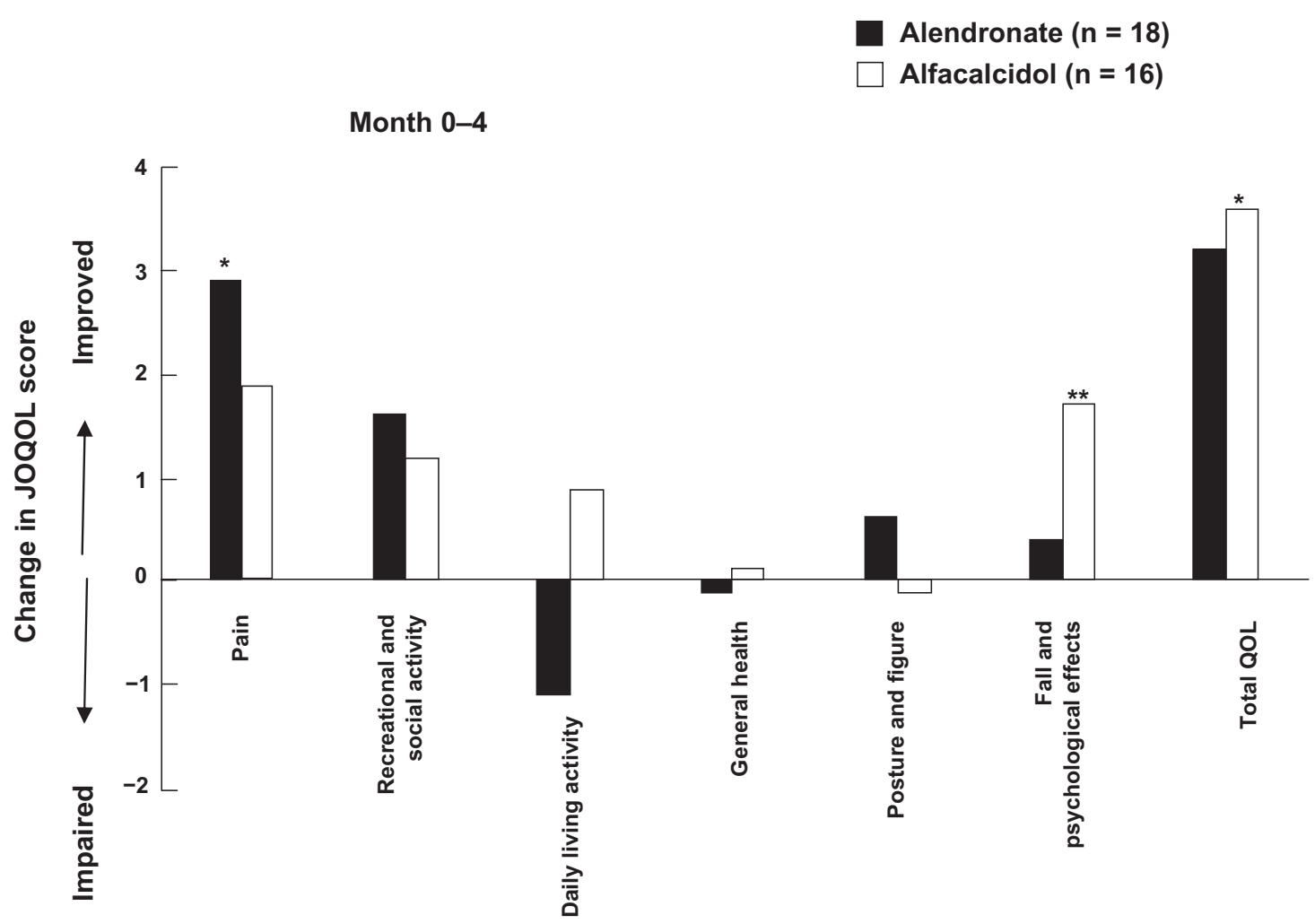

Figure 2 Comparison of JOQOL score changes in pain, recreational and social activity, daily living activity, general health, posture and figure, fall and psychological effects and total, between alendronate and alfacalcidol treatments during the first 4 months. Increased score indicates improvement of QOL.

Note: $* p<0.05$, $* * p<0.01$ vs baseline.

Abbreviation: JOQOL, Japanese Osteoporosis Quality of Life Questionnaire; QOL, quality of life. 
Month 0-4

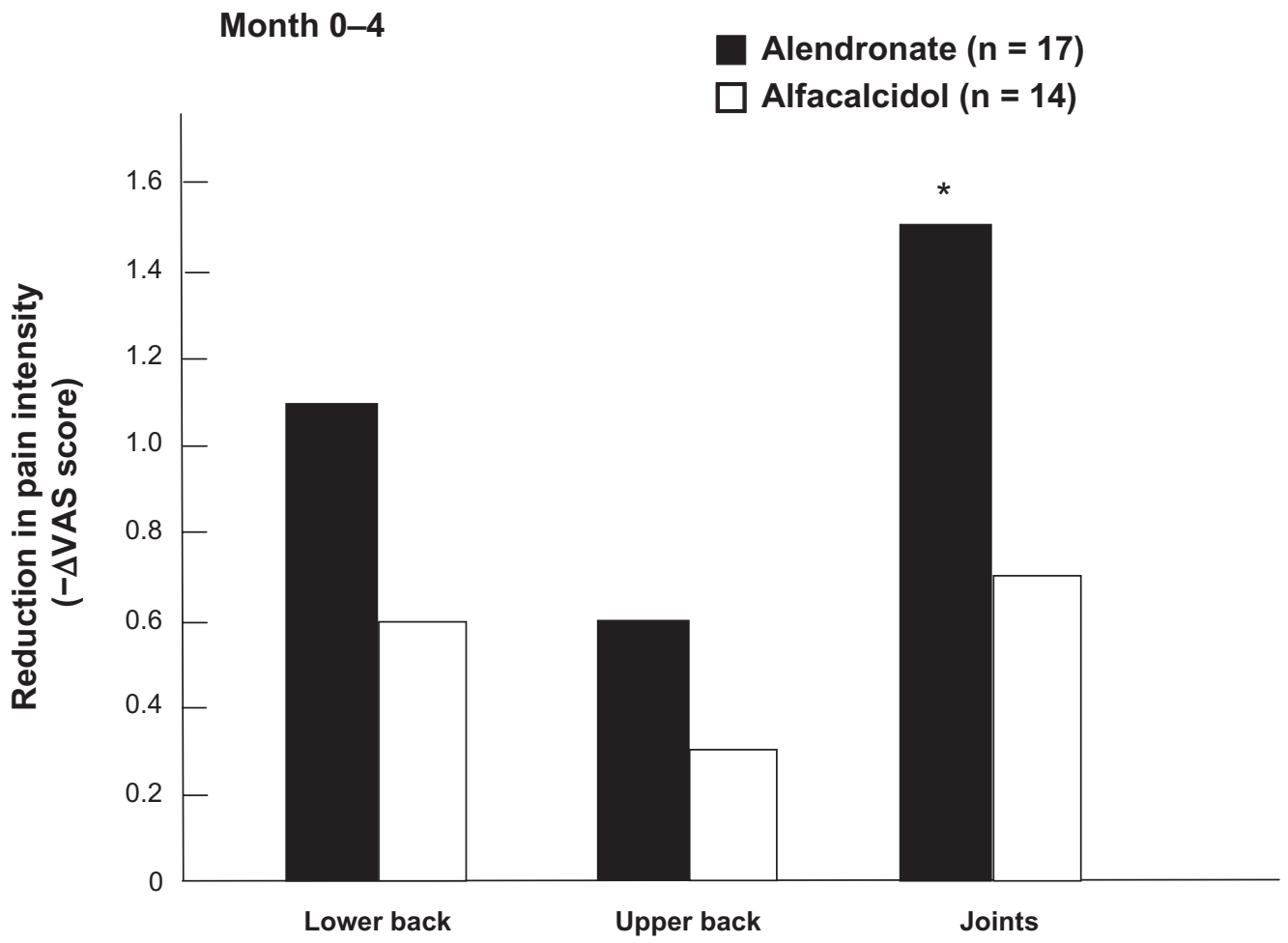

Figure 3 Comparison of pain intensity reduction between alendronate and alfacalcidol treatments during the first 4 months according to visual analog scale of I0 points. Pain was assessed in lower back, upper back and joints.

Note: $* P<0.05$ vs baseline.

suppressed the bone resorption more than alfacalcidol $(-57 \%$ versus $-18 \%, P<0.001)$ as shown in Figure $4 \mathrm{~b}$.

\section{Crossover}

After the first 4-month treatment, the patients were followed for 2 months after the crossover to the other drug. A total of 13 patients in the group A received alfacalcidol and 10 patients in the group $\mathrm{B}$ received alendronate. The two groups had similar patient characteristics (except age) at the end of the first 4-month treatment. Mean age was significantly lower in the group A than in the group B (age 65.9 \pm 8.8 years versus $73.6 \pm 5.1$ years, $P<0.05$ ) as shown in Table 2 .
A

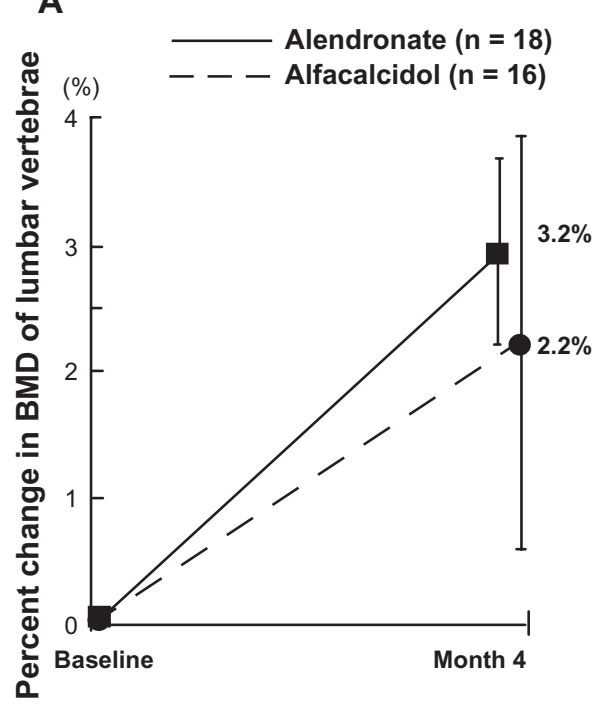

B

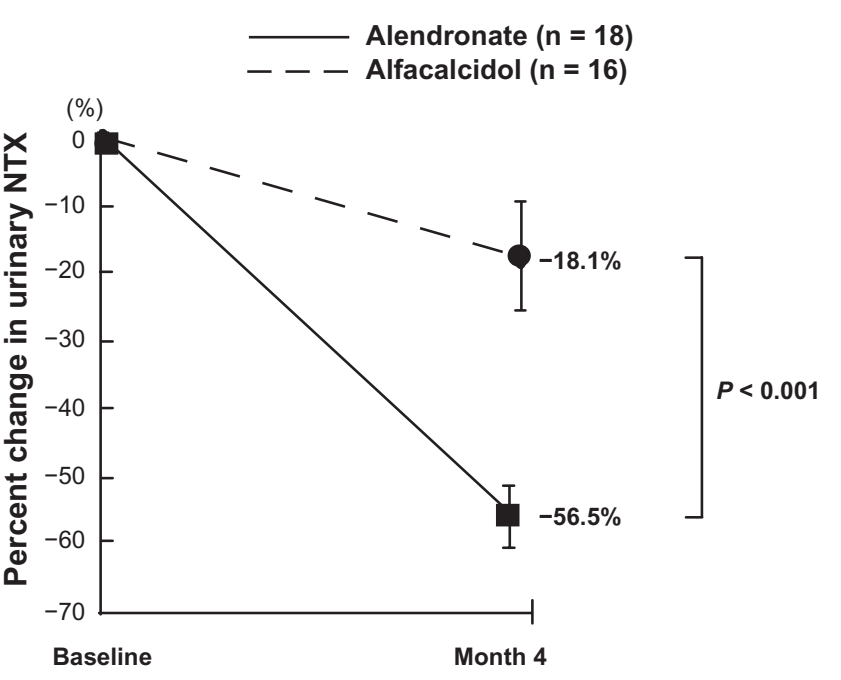

Figure 4 Comparison of percent changes in BMD of lumbar vertebrae A) and urinary NTX B) between alendronate and alfacalcidol treatments during the first 4 months of the treatments.

Abbreviations: BMD, bone mineral density; NTX, urinary crosslinked N-terminal telopeptide of type I collagen. 
During the 2 months after the crossover, the total QOL scores and the daily living activity related QOL score were decreased in the group A that had switched from alendronate to alfacalcidol. No significant changes were observed in total, and "posture and figure" related QOL in the group B which switched from alfacalcidol to alendronate. However, total QOL and posture and figure related QOL increased significantly in the group B taking alendronate than compared with group A, now taking alfacalcidol, during the 2 month post-crossover period. This suggests that alendronate suppressed any decrease in QOL in group B, as shown in Figure 5.

According to pain intensity evaluated by VAS, group A had significantly increased upper back pain when taking alfacalcidol in the 2-month post-crossover period, while group B had no significant change in pain intensity with alendronate in any of the studied regions. No significant difference was observed in pain intensity changes between the two groups (Figure 6). These results suggest that switching to alfacalcidol from alendronate caused a decrease in QOL and increased pain.

Bone resorption measured by NTX was significantly increased in group A, which switched to alfacalcidol during the 2 month post-crossover period, $(20.3 \pm 6.2$ to $28.4 \pm 9.1 \mathrm{nM}$ bone collagen-equivalent $[\mathrm{BCE}] / \mathrm{nM}$ creatinine [Cr], while NTX was significantly decreased in the group B that switched to alendronate. This suggests that alendronate significantly suppresses the bone resorption more than alfacalcidol $(P<0.01)$ as shown in Figure 7.

\section{Discussion}

The present study demonstrated that alendronate improved the QOL, especially pain related QOL, in postmenopausal osteoporotic Japanese women. The improvement in pain related QOL by alendronate was supported by the VAS pain intensity measurement; alendronate significantly reduced pain in the joints, and reduced any exacerbation of pain in the back, suggesting that pain reduction by alendronate contributed to the improvement of overall QOL in the patients.

The JOQOL questionnaire was created by the Japanese Society for Bone and Mineral Research to evaluate the QOL of Japanese osteoporotic patients based on the Osteoporosis Assessment Questionnaire in USA and the Questionnaire for Quality of Life by European Foundation for Osteoporosis (Qualeffo-42). It is a modification of the two questionnaires with additional questions that are suitable to the life style of Japanese women. According to the paper by Takahashi and colleagues, the JOQOL scores are correlated to the scores of Medical Outcomes Study Short Form 36 (SF-36) with coefficient $r=0.78$ and reproducibility $(r=0.92) .{ }^{11}$

Although total QOL scores showed an increased trend with both alendronate and alfacalcidol in the first 4 months,

Table 2 Patient baseline characteristics after crossover

\begin{tabular}{|c|c|c|c|c|}
\hline Characteristic & & Group $A(n=18)$ alendronate & Group B $(n=16)$ alfacalcidol & $P$ value \\
\hline Age (year) & & $66.7 \pm 9.1$ & $73.6 \pm 5.1$ & $<0.05$ \\
\hline BMD Lumbar vertebrae $\left(\mathrm{g} / \mathrm{cm}^{2}\right)$ & & $0.639 \pm 0.147$ & $0.613 \pm 0.164$ & ns \\
\hline Urinary NTX (nmol BCE/nmol Cr) & & $49.0 \pm 10.8$ & $49.2 \pm 23.6$ & ns \\
\hline Vertebral fractures at baseline (yes/no) & & $3 / 9$ & $2 / 8$ & ns \\
\hline Family history of osteoporosis (yes/no) & & $2 / 11$ & $5 / 5$ & ns \\
\hline VAS (lower back) & & $5.0 \pm 2.8$ & $3.8 \pm 1.4$ & ns \\
\hline VAS (upper back) & & $3.3 \pm 2.3$ & $3.3 \pm 2.4$ & ns \\
\hline VAS (joints) & & $4.2 \pm 2.1$ & $2.5 \pm 1.7$ & ns \\
\hline \multicolumn{5}{|l|}{ JOQOL } \\
\hline Pain & (20 points) & $\mathrm{II} .4 \pm 4.7$ & $13.8 \pm 4.1$ & ns \\
\hline Activity of daily living & (64 points) & $57.2 \pm 8.9$ & $55.0 \pm 12.7$ & ns \\
\hline Recreational and social activities & (20 points) & $11.6 \pm 4.8$ & $7.9 \pm 5.0$ & ns \\
\hline General health & ( 12 points) & $7.3 \pm 3.9$ & $7.5 \pm 3.4$ & ns \\
\hline Posture and figure & (16 points) & $11.5 \pm 4.0$ & $9.9 \pm 2.8$ & ns \\
\hline Falls and the psychological effects & (20 points) & $12.8 \pm 4.3$ & $11.3 \pm 4.2$ & ns \\
\hline Total QOL score & (I52 points) & $72.8 \pm 13.8$ & $69.3 \pm 11.6$ & ns \\
\hline
\end{tabular}

Abbreviations: NS, not significant; QOL, quality of life; VAS, visual analog scale; JOQOL, Japanese Osteoporosis Quality of Life Questionnaire; BMD, bone mineral density; $\mathrm{NTX}$, urinary crosslinked $\mathrm{N}$-terminal telopeptide of type I collagen; BCE, bone collagen-equivalent; $\mathrm{Cr}$, creatinine. 
Month 4-6

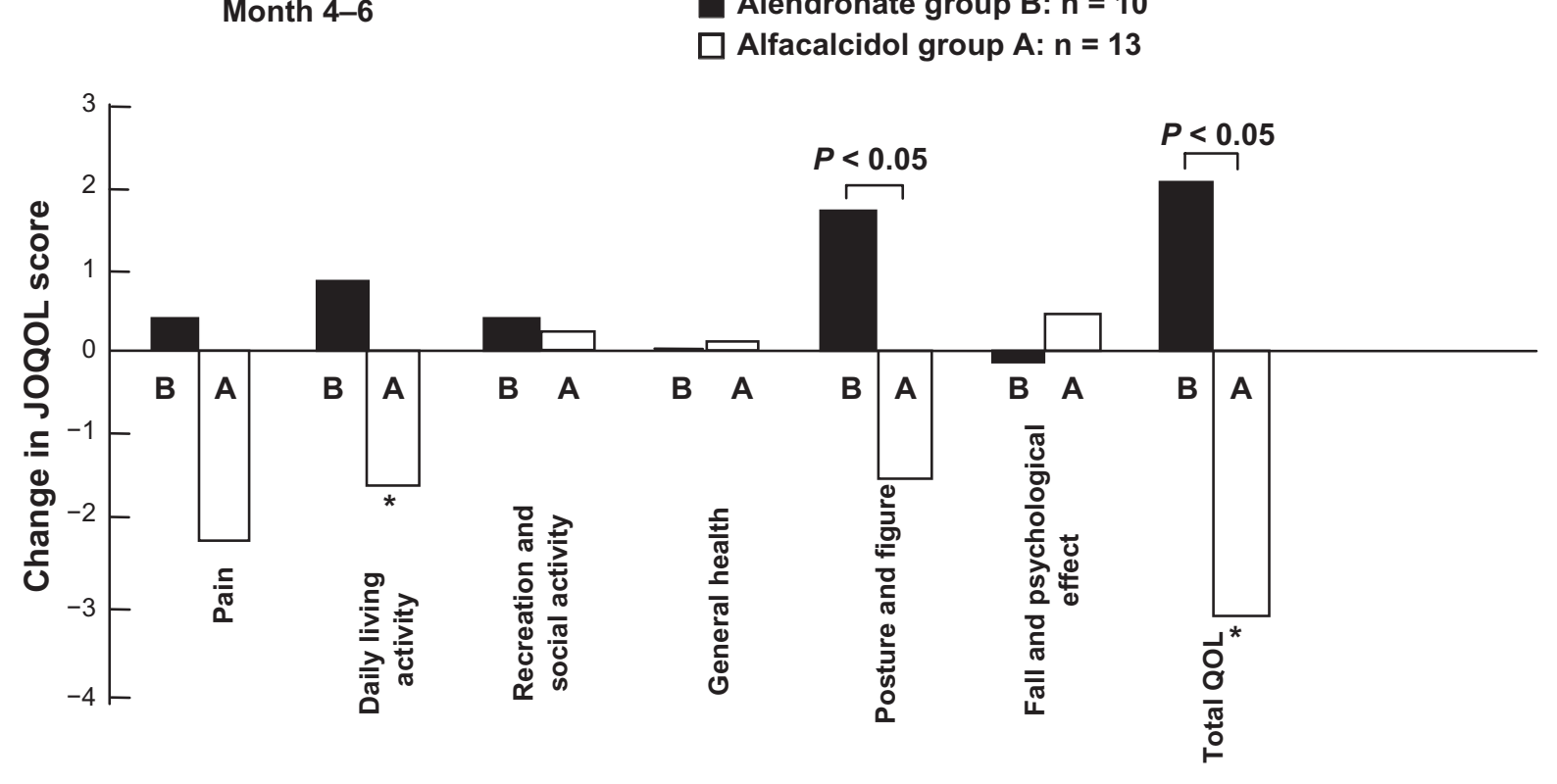

Alendronate group $B: \mathbf{n}=10$

Alfacalcidol group $A: n=13$

Figure 5 Comparison of in JOQOL score changes in pain, recreational and social activity, daily living activity general health, posture and figure, fall and psychological effect, and total between alendronate and alfacalcidol treatments during 2 months after the crossover. Increased score indicates improvement of QOL.

Note: $* P<0.001$ vs month 4 .

Abbreviation: JOQOL, Japanese Osteoporosis Quality of Life Questionnaire; QOL, quality of life.

the significant improvement of the total QOL was found only with alfacalcidol in the present study. However, among the QOL of six categories, alendronate significantly improved pain related QOL. In several previous studies, QOL improvement and pain reduction occurred with alendronate. Nevitt and colleagues demonstrated in a large scale 3-year randomized double blind study that alendronate reduced the number of days disability spent in bed, and the days of

\section{Month 4-6}

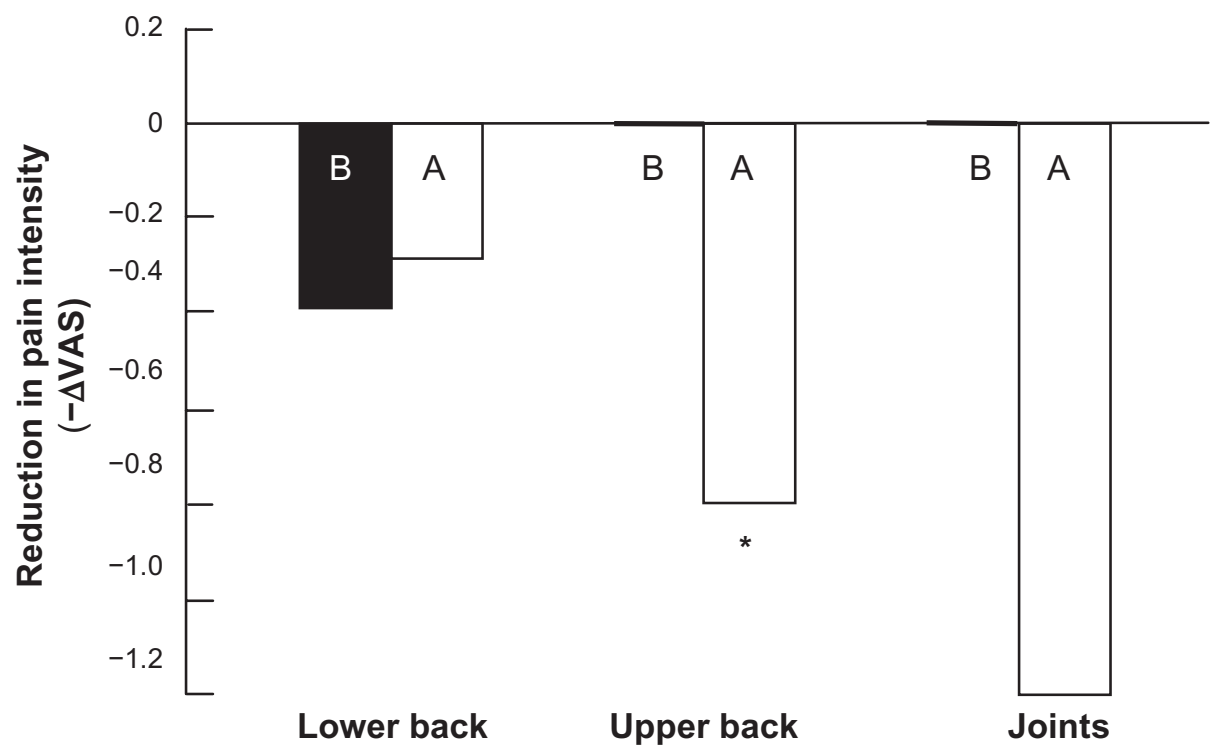

Figure 6 Comparison of pain intensity reduction between alendronate and the alfacalcidol treatments during 2 months after the crossover according to visual analog scale of 10 points. Pain was assessed in lower back, upper back and joints.

Note: $* P<0.05$ vs month 4

Abbreviation: $\triangle \mathrm{VAS}$, change in visual analog scale. 


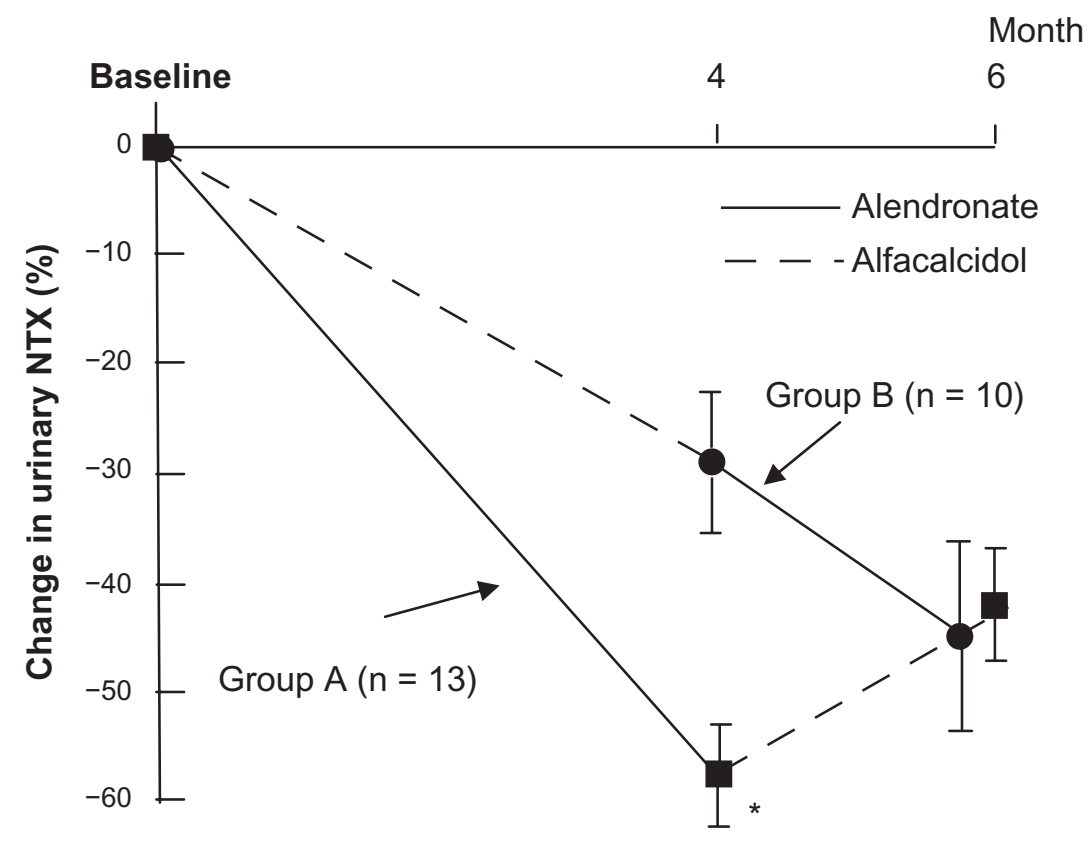

Figure 7 Comparison of percentage changes in urinary NTX between alendronate and alfacalcidol treatments during 6 months of the treatment including 2 months after the crossover.

Note: $* P<0.05$ vs alfacalcidol.

Abbreviation: NTX, urinary crosslinked N-terminal telopeptide of type I collagen.

limited activities caused by low back pain. ${ }^{4}$ Moreover, Dursun and colleagues showed that alendronate and calcitonin reduced pain and improved the QOL equally after 6-months of treatment, when alendronate, calcitonin and calcium were compared for pain reduction, - when assessed by VAS and QOL improvement - as evaluated by the Nottingham Health Profile in an open-labeled study. ${ }^{\text {? }}$

The mechanism alendronate improves pain has not been clarified. The reduced incidence of bone fracture by alendronate was suggested to reduce the pain. ${ }^{4}$ However in our study no new fractures were observed during the study period and the effect of alendronate on reducing pain appeared relatively quickly after the commencement of treatment. A marker for bone resorption, NTX, was decreased more with alendronate than with alfacalcidol. Although markers for bone metabolism and pain or QOL were not significantly associated in such a small scale study as ours, NTX reduction was positively associated with low back pain in 80 post menopausal women with osteoporosis reported by Iwamoto and colleagues. ${ }^{8}$ In patients with bone metastases or multiple myeloma, an intravenous treatment of bisphosphonates was shown to relieve skeletal pain within several weeks of the commencement of treatment. ${ }^{12-14}$ The timing for onset of the positive effects of the drug suggests that the effects of bisphosphonates on bone pain may not be explicitly related to an anti-osteoporotic effect, and likely to be associated with another mechanism of pain reduction. ${ }^{15}$

Within the local bone lesions, elevated inflammatory cytokines, prostaglandin and growth factors stimulate osteoclast activity and nociceptors to cause bone pain. ${ }^{16,17}$ Since bisphosphonates were shown to reduce osteoclastogenic cytokines, ${ }^{18,19}$ this may explain the pain relieving effect. However, osteoclasts are known to degrade bone minerals by secreting protons through the vacuolar $\mathrm{H}^{+}-$ ATPase, creating acidic microenvironments. ${ }^{20-22}$ Nagae and colleagues ${ }^{23}$ proposed that osteoclasts plays an important role in producing bone pain by creating acidosis and through activating acid-sensing receptors of sensory neurons. In the study, bisphosphonates suppressed inflammatory hyperalgesia by inhibiting the effect of osteoclasts in the animal model.

There are limitations in the present study. The number of study patients is small and some baseline patient characteristics were different between the groups; group A had a lower number of patients with a family history of osteoporosis and a slightly lower QOL in recreational and social activities when compared with the group B. This study was carried out as an open label study. There may be bias in the effect of the drugs. To confirm the results, a large double blind study must be conducted. 


\section{Conclusion}

Alendronate significantly suppressed pain when measured by a VAS, and by patient QOL measured by JOQOL, in postmenopausal osteoporotic patients. The efficacy of alendronate is higher than that of alfacalcidol. The long term treatment of osteoporosis with alendronate not only prevents bone fracture, but also improves the patient's QOL and reduces pain or prevents the exacerbation of pain.

\section{Acknowledgments}

We gratefully thank Dr Ken-ichi Sugi, Dr Kazumoto Kawate, Dr Naoto Tokunaga, Dr Tatsuhiko Masuda, Dr Satoru Nakate, Dr Hideyo Matsuguchi, Dr Seiichi Goto and Ms Yoshie Ohga for contributing this project. This work was supported in part by Grants-in-Aid from the Ministry of Education, Culture, Sports, Science and Technology, Japan (Scientific Research $\mathrm{B}$ and $\mathrm{C})$.

\section{Disclosures}

The authors report no conflicts of interest relevant to this work.

\section{References}

1. Gold DT. The clinical impact of vertebral fractures: quality of life in women with osteoporosis. Bone. 1996;18(3 Suppl):185S-189S.

2. Randell AG, Nguyen TV, Bhalerao N, Silverman SL, Sambrook PN, Eisman JA. Deterioration in quality of life following hip fracture: a prospective study. Osteoporos Int. 2000;11(5):460-466.

3. Oleksik A, Lips P, Dawson A, et al. Health-related quality of life in postmenopausal women with low BMD with or without prevalent vertebral fractures. J Bone Miner Res. 2000;15(7):1384-1392.

4. Nevitt MC, Thompson DE, Black D, et al. Effect of alendronate on limited activity days and bed-disability days caused by back pain in postmenopausal women with existing vertebral fractures. Arch Intern Med. 2000;160(1):77-85.

5. Martin AR, Sornay-Rendu E, Chandler JM, Duboeuf F, Girman CJ, Delmas PD. The impact of osteoporosis on quality-of-life: the OFELY cohort. Bone. 2002;31(1):32-36.

6. Ethgen O, Tellier V, Sedrine WB, De Maeseneer J, Gosset C, Reginster JY. Health-related quality of life and cost of ambulatory care in osteoporosis: how may such outcome measures be valuable information to health decision makers and payers? Bone. 2003;32(6):718-724.

7. Dursun N, Dursun E, Yalcin S. Comparison of alendronate, calcitonin and calcium treatments in postmenopausal osteoporosis. Int J Clin Pract. 2001;55(8):505-509.
8. Iwamoto J, Takeda T, Sato Y, Uzawa M. Effects of alendronate on metacarpal and lumbar bone mineral density, bone resorption, and chronic back pain in postmenopausal women with osteoporosis. Clin Rheumatol. 2004;23(5):383-389.

9. Kushida K, Fukunaga M, Kishimoto H, et al. A comparison of incidences of vertebral fracture in Japanese patients with involutional osteoporosis treated with risedronate and etidronate: a randomized, double-masked trial. J Bone Miner Metab. 2004;22(5):469-478.

10. Itami Y, Fujita T, Inoue T, et al. Effect of alphacalcidol $\left(1 \alpha-\mathrm{OH}-\mathrm{D}_{3}\right)$ on osteoporosis - a multicentre double-blind study. Igaku No AyumiJ Clin Exper Med. 1982;123:958-973 (in Japanese).

11. Takahashi H, Iwaya C. The Japanese Osteoporosis QOL Questionnaire (JOQOL): 2000 edition. J Jpn Soc Bone Miner Res. 2001;18:83-101 (in Japanese).

12. Berenson JR, Lichtenstein A, Porter L, et al. Efficacy of pamidronate in reducing skeletal events in patients with advanced multiple myeloma. Myeloma Aredia Study Group. N Engl J Med. 1996;334(8):488-493.

13. Hortobagyi GN, Theriault RL, Porter L, et al. Efficacy of pamidronate in reducing skeletal complications in patients with breast cancer and lytic bone metastases. Protocol 19 Aredia Breast Cancer Study Group. N Engl J Med. 1996;335(24):1785-1791.

14. Fulfaro F, Casuccio A, Ticozzi C, Ripamonti C. The role of bisphosphonates in the treatment of painful metastatic bone disease: a review of phase III trials. Pain. 1998;78(3):157-169.

15. Pappagallo M, Breuer B, Schneider A, Sperber K. Treatment of chronic mechanical spinal pain with intravenous pamidronate: a review of medical records. J Pain Symptom Manage. 2003;26(1):678-683.

16. Watkins LR, Maier SF, Goehler LE. Immune activation: the role of pro-inflammatory cytokines in inflammation, illness responses and pathological pain states. Pain. 1995;63(3):289-302.

17. Payne R. Mechanisms and management of bone pain. Cancer. 1997;80(Suppl 8):1608-1613.

18. Cantatore FP, Acquista CA, Pipitone V. Evaluation of bone turnover and osteoclastic cytokines in early rheumatoid arthritis treated with alendronate. J Rheumatol. 1999;26(11):2318-2323.

19. D'Amelio P, Grimaldi A, Di Bella S, et al. Risedronate reduces osteoclast precursors and cytokine production in postmenopausal osteoporotic women. J Bone Miner Res. 2008;23(3):373-379.

20. Blair HC, Teitelbaum SL, Ghiselli R, Gluck S. Osteoclastic bone resorption by a polarized vacuolar proton pump. Science. 1989;245(4920):855-857.

21. Mattsson JP, Schlesinger PH, Keeling DJ, Teitelbaum SL, Stone DK, Xie XS. Isolation and reconstitution of a vacuolar-type proton pump of osteoclast membranes. J Biol Chem. 1994;269(40):24979-24982.

22. Li YP, Chen W, Liang Y, Li E, Stashenko P. Atp6i-deficient mice exhibit severe osteopetrosis due to loss of osteoclast-mediated extracellular acidification. Nat Genet. 1999;23(4):447-451.

23. Nagae M, Hiraga T, Wakabayashi H, Wang L, Iwata K, Yoneda T. Osteoclasts play a part in pain due to the inflammation adjacent to bone. Bone. 2006;39(5):1107-1115.
Clinical Interventions in Aging

\section{Publish your work in this journal}

Clinical Interventions in Aging is an international, peer-reviewed journa focusing on evidence-based reports on the value or lack thereof of treatments intended to prevent or delay the onset of maladaptive correlates of aging in human beings. This journal is indexed on PubMed Central, MedLine, the American Chemical Society's 'Chemical Abstracts Ser-

\section{Dovepress}

vice' (CAS), Scopus and the Elsevier Bibliographic databases. The manuscript management system is completely online and includes a very quick and fair peer-review system, which is all easy to use. Visit http://www.dovepress.com/testimonials.php to read real quotes from published authors. 